Article

\title{
Population Dynamics between Erwinia amylovora, Pantoea agglomerans and Bacteriophages: Exploiting Synergy and Competition to Improve Phage Cocktail Efficacy
}

\author{
Steven Gayder ${ }^{1,2} \mathbb{D}$, Michael Parcey ${ }^{1,2} \mathbb{D}$, Darlene Nesbitt ${ }^{2}$, Alan J. Castle ${ }^{3}$ \\ and Antonet M. Svircev ${ }^{2, *}$ \\ 1 Centre for Biotechnology, Brock University, St. Catharines, ON L2S 3A1, Canada; sg10yl@brocku.ca (S.G.); \\ mp1711@brocku.ca (M.P.) \\ 2 Agriculture and Agri-Food Canada, Vineland Station, ON L0R 2E0, Canada; darlene.nesbitt@canada.ca \\ 3 Department of Biological Sciences, Brock University, St. Catharines, ON L2S 3A1, Canada; acastle@brocku.ca \\ * Correspondence: antonet.svircev@canada.ca; Tel.: +1-905-562-2018
}

Received: 21 August 2020; Accepted: 17 September 2020; Published: 22 September 2020

check for updates

\begin{abstract}
Bacteriophages are viruses capable of recognizing with high specificity, propagating inside of, and destroying their bacterial hosts. The phage lytic life cycle makes phages attractive as tools to selectively kill pathogenic bacteria with minimal impact on the surrounding microbiome. To effectively harness the potential of phages in therapy, it is critical to understand the phage-host dynamics and how these interactions can change in complex populations. Our model examined the interactions between the plant pathogen Erwinia amylovora, the antagonistic epiphyte Pantoea agglomerans, and the bacteriophages that infect and kill both species. P. agglomerans strains are used as a phage carrier; their role is to deliver and propagate the bacteriophages on the plant surface prior to the arrival of the pathogen. Using liquid cultures, the populations of the pathogen, carrier, and phages were tracked over time with quantitative real-time PCR. The jumbo Myoviridae phage $\phi E a 35-70$ synergized with both the Myoviridae $\phi E$ 21-4 and Podoviridae $\phi E a 46-1-A 1$ and was most effective in combination at reducing E. amylovora growth over $24 \mathrm{~h}$. Phage $\phi E a 35-70$, however, also reduced the growth of P. agglomerans. Phage cocktails of $\phi E a 21-4, \phi E a 46-1-A 1$, and $\phi E a 35-70$ at multiplicities of infections (MOIs) of 10, 1, and 0.01, respectively, no longer inhibited growth of P. agglomerans. When this cocktail was grown with $P$. agglomerans for $8 \mathrm{~h}$ prior to pathogen introduction, pathogen growth was reduced by over four log units over $24 \mathrm{~h}$. These findings present a novel approach to study complex phage-host dynamics that can be exploited to create more effective phage-based therapies.
\end{abstract}

Keywords: fire blight; phage carrier; bacteriophages; qPCR; phage-host dynamics; phage cocktails; phage therapy

\section{Introduction}

Bacteriophages, or phages, are bacterial viruses that infect and replicate within their host [1]. Lytic phages subsequently rupture and kill their bacterial host, releasing new phage progeny that can infect other nearby hosts to continue this life cycle. Phages can identify their host with great specificity and therefore play a large role in shaping microbial communities [1]. The overuse of antibiotics has led to a global health crisis of widespread antibiotic resistance and has significantly impacted the environment via the soil and its associated microbial communities [2,3]. Phages have therefore seen a recent resurgence of interest for their potential use as antimicrobial agents to replace or supplement antibiotics for the control of human, animal, and plant pathogens [3-5]. Understanding the factors 
that determine the success or failure of phage therapy is important for the development of successful therapeutic applications [4]. Phage-host interactions such as host range, burst size, adsorption rate, and time to lysis are often critical determinants in choosing phages for cocktails or mixtures, while mathematical models have sought to understand how these factors interact to achieve successful control $[4,6]$.

The plant pathogen Erwinia amylovora causes the disease commonly referred to as fire blight in apples, pears, and other members of the Rosaceae. Originally native to North America, E. amylovora has spread worldwide and is present in many fruit-growing regions of the world [7]. Infection of trees commences when the nutrient-rich stigma of open blossoms is exposed to E. amylovora and the pathogen begins to replicate. The pathogen continues to colonize the stigma until high humidity or a wetting event washes cells into the nectarthodes located in the floral cup [8]. This allows the bacteria to enter the tree and spread throughout the vasculature of the host plant, leading to wilt, necrosis, and potential death of the entire tree [9]. Temporal factors and weather conditions can make effective control with biological control agents or biologicals very challenging. Open blossoms can be rapidly colonized by upwards of 30 bacterial phyla of epiphytic microbes [10,11]. From the initial blossom opening to petal fall, this microbial diversity is greatly reduced as Proteobacteria come to make up $>99 \%$ of the microbiota, most of which is also almost entirely Enterobacteriaceae and Pseudomonadaceae [10]. Management of fire blight largely consists of alteration of the microbiota resulting in pathogen reduction on the open blossoms [10]. Antibiotics are the preferred means of control for growers, but as some countries ban their use and antimicrobial resistance spreads there is a growing interest in the use of biologicals within integrated pest management (IPM) strategies [5,12].

Pantoea agglomerans is an epiphytic bacterium found in the orchard ecosystem or phyllosphere. P. agglomerans has shown antagonistic properties against E. amylovora through competitive exclusion and production of antimicrobials [13]. P. agglomerans strain E325 is the active ingredient of the commercial biological product Bloomtime [14]. Additionally, Erwinia lytic phages are capable of infecting P. agglomerans, and together have been studied for their potential as an additional means of E. amylovora control [15]. In this phage-mediated biological control system, phage infected P. agglomerans strains (termed the carrier) are applied to the blossom. These carrier cells are used to increase the phage population in vivo and any non-infected cells may act as a biological control agent [15]. Therefore, understanding the dynamics and interactions between P. agglomerans antagonism and phage lysis is critical to harness any potential synergy for E. amylovora control.

The lytic phages of E. amylovora in our collection belong to four species: the Kolesnikvirus Erwinia virus Ea214 and Agricanvirus Erwinia virus Ea35-70 of the Myoviridae family, and the Eracentumvirus Erwinia virus Era103 and Johnsonvirus Erwinia virus Ea9-2 of the Podoviridae family. The biggest known determinant of host range is the exopolysaccharide (EPS) production, particularly amylovoran [16,17]. Erwinia virus Era103 phages require amylovoran for infection and prefer hosts with higher EPS production while Erwinia virus Ea214 phages prefer lower producers of EPS [16,17]. The effect of EPS preferences on phage production is greater in strains from the Western regions of North America, but the cause of this is not known [16]. The Erwinia virus Ea35-70 phage does not follow these trends and is generally much less successful at infecting E. amylovora, and therefore even less is known about its infection strategy [16].

Studies of in vitro phage-host interactions in liquid culture commonly use optical density to compare bacterial growth dynamics in response to different phage treatments [18-23]. Optical density measurements are quick and amenable to high-throughput comparison using 96-well incubating spectrophotometers, and hosts can even be fluorescently labeled to allow differentiation [24]. However, phage quantification in these cultures, especially those with phage mixtures, is frequently avoided due to the extra effort required and inability to quantitatively differentiate multiple phages. Real-time quantitative PCR (qPCR) is a rapid and reproducible alternative to the double agar overlay for phage quantification [25]. qPCR makes it possible, by differentially quantifying the genomes in solution, to individually track multiple bacteria and phages in mixed cultures. Previously, we used 
qPCR to determine the host range of 10 phages against a global collection of E. amylovora [16] and to create a molecular profile of phage infection to measure adsorption, burst size, latency period, and time to burst [26].

The objective of this study was to investigate the complex dynamics between the pathogen E. amylovora, the epiphytic phage carrier P. agglomerans, and several combinations of Erwinia spp. phages. The aim was to identify possible interspecies phage interactions that could enhance the control of the pathogen E. amylovora or survival of the carrier P. agglomerans. Growth of combinations of different species of Myoviridae and Podoviridae, and of E. amylovora and P. agglomerans were assessed by qPCR. This work represents the first step in understanding the complex interactions between phage, pathogen, and epiphyte in the orchard.

\section{Materials and Methods}

\subsection{Bacterial Isolates}

All bacterial strains used in this study are listed in Table 1 . All cultures were stored at $-80^{\circ} \mathrm{C}$ in Microbank cryobeads (Pro-Bank Diagnostics, Richmond Hill, ON, Canada). Cultures were initially spread onto 2.3\% Difco nutrient agar (NA; BD, Sparks, MD, USA) using one cryobead. These cultures were grown overnight at $27^{\circ} \mathrm{C}$ and stored at $4{ }^{\circ} \mathrm{C}$ for 1 to 2 weeks. Working subcultures were obtained from the initial cultures, plated onto NA, and grown at $27^{\circ} \mathrm{C}$ overnight or over 2 to 3 days at room temperature.

Table 1. Strains of bacteria used in this study.

\begin{tabular}{ccc}
\hline Strain & Accession Number & Reference \\
\hline Erwinia amylovora & & \\
Ea17-1-1 & JAAEVW000000000 & {$[16]$} \\
EaD7 & JAAEUT000000000 & {$[16]$} \\
Ea6-4 & JAAEVD000000000 & {$[16]$} \\
Ea29-7 & JAAEVM000000000 & {$[16]$} \\
20060013 & JAAEXH000000000 & {$[16,27]$} \\
20070126 & JAAEXF000000000 & {$[16,27]$} \\
\hline Pantoea agglomerans & & \\
Pa17-1 & JACSXN000000000 & {$[28]$} \\
Pa17-5 & JACSXM000000000 & {$[28]$} \\
Pa21-3 & JACSXL000000000 & {$[28]$} \\
Pa21-5 & JACSXK000000000 & {$[28]$} \\
Pa21-13 & JACSXI000000000 & {$[28]$} \\
Pa21-15 & JACSXH000000000 & {$[28]$} \\
Pa31-3 & JACSXF000000000 & {$[28]$} \\
Pa31-4 & JACSXE000000000 & {$[28]$} \\
Pa39-1 & JACSXC000000000 & {$[28]$} \\
Pa39-3 & JACSXB000000000 & {$[28]$} \\
Pa39-5 & JACSXA000000000 & {$[28]$} \\
Pa39-7 & JACSWZ000000000 & {$[28]$} \\
Pa39-14 & JACSWY000000000 & {$[28]$} \\
Pa39-21 & JACSWX000000000 & {$[28]$} \\
Pa39-23 & JACSWW000000000 & {$[28]$} \\
Pa39-27 & JACSWV000000000 & {$[28]$} \\
E325 & JACSWT000000000 & {$[14]$} \\
E325-699 & JACSWS000000000 & {$[14]$} \\
E325-705 & JACSWR000000000 & {$[14]$} \\
E325-750 & JACSWQ000000000 & {$[14]$} \\
E325-754 & JACSWP000000000 & {$[14]$} \\
E325-ad1 & JACSWO000000000 & {$[14]$} \\
E325-ad2 & JACSWN000000000 & {$[14]$} \\
\hline & & \\
\hline
\end{tabular}


Table 1. Cont.

\begin{tabular}{ccc}
\hline $\begin{array}{c}\text { Pantoea eucalypti } \\
\text { Pv21-6 }\end{array}$ & JACSXJ000000000 & {$[28]$} \\
\hline $\begin{array}{c}\text { Erwinia gerundensis } \\
\text { Eg13-2 }\end{array}$ & JACSXP000000000 & {$[28]$} \\
Eg13-3 & JACSXO000000000 & {$[28]$} \\
Eg31-2 & JACSXG000000000 & {$[28]$} \\
Eg31-5 & JACSXD000000000 & {$[28]$} \\
\hline Rahnella aquatilis & & \\
Ra9-2 & JACSXQ000000000 & {$[28]$} \\
\hline Pantoea sp. & & \\
Psp39-30 & JACSWU000000000 & {$[28]$} \\
\hline
\end{tabular}

\subsection{Bacteriophage Propagation}

A bacterial suspension of the phage's specific propagation host (Table 2) was created by scraping cells from a NA plate into $3 \mathrm{~mL}$ of $0.8 \%$ nutrient broth (NB; BD, Sparks, MD, USA) and adjusting to an $\mathrm{OD}_{600}$ of 0.6 . Using a $250 \mathrm{~mL}$ baffled Erlenmeyer flask, we added $100 \mu \mathrm{L}$ bacterial suspension to $75 \mathrm{~mL}$ $\mathrm{NB}$, which was incubated at $27^{\circ} \mathrm{C}$ and $125 \mathrm{rpm}$ for 3-4 h. To this culture, we added $100 \mu \mathrm{L}$ of phage stock, and the mixture was incubated overnight. The following morning, we added $1 \mathrm{~mL}$ chloroform to the flask, which was shaken at $125 \mathrm{rpm}$ for about $5 \mathrm{~min}$. The culture was centrifuged at $8500 \times g$ at $4{ }^{\circ} \mathrm{C}$ for $15 \mathrm{~min}$, and the supernatant was filtered through a $0.22 \mu \mathrm{m}$ Steriflip filter (Millipore, Billerica, MA, USA). These working phage stocks were stored at $4{ }^{\circ} \mathrm{C}$ in dark amber glass vials.

Table 2. Phages used in this study.

\begin{tabular}{|c|c|c|c|c|c|c|}
\hline Phage & Family & Genus & Species & $\begin{array}{l}\text { Accession } \\
\text { Number }^{\text {a }}\end{array}$ & $\begin{array}{c}\text { Propagation } \\
\text { Host }\end{array}$ & Reference \\
\hline$\phi$ Ea10-1 & Myoviridae & Kolesnikvirus & $\begin{array}{l}\text { Erwinia virus } \\
\text { Ea214 }\end{array}$ & NA & Ea17-1-1 & [29] \\
\hline$\phi \mathrm{Ea} 10-2$ & & & & NA & Ea6-4 & [29] \\
\hline$\phi E a 21-4$ & & & & NC_011811.1 & Ea6-4 & {$[29,30]$} \\
\hline$\phi \mathrm{Ea} 45-1 \mathrm{~B}$ & & & & NA & Ea6-4 & [29] \\
\hline$\phi$ Еa35-70 & & Agricanvirus & $\begin{array}{l}\text { Erwinia virus } \\
\text { Ea35-70 }\end{array}$ & NC_023557.1 & Pa39-7 & {$[29,31]$} \\
\hline$\phi$ Ea10-7 & Podoviridae & Eracentumvirus & $\begin{array}{l}\text { Erwinia virus } \\
\text { Era103 }\end{array}$ & NA & Ea29-7 & [29] \\
\hline$\phi$ Ea31-3 & & & & NA & Ea29-7 & [29] \\
\hline$\phi \mathrm{Ea} 46-1-\mathrm{A} 1$ & & & & NA & EaD7 & [29] \\
\hline$\phi \mathrm{Ea} 46-1-\mathrm{A} 2$ & & & & NA & EaD7 & [29] \\
\hline$\phi \mathrm{Ea} 9-2$ & & Johnsonvirus & $\begin{array}{c}\text { Erwinia virus } \\
\text { Ea9-2 }\end{array}$ & NC_023579.1 & Ea17-1-1 & [29] \\
\hline
\end{tabular}

NA: No accession number available, genomes are not deposited. ${ }^{a}$ The accession number for $\phi$ Era103 is NC_009014.1.

Titers of working phage stocks were determined with qPCR (Section 2.3) after treatment with DNase I to remove non-encapsidated genomes. To $10 \mu \mathrm{L}$ phage lysate, we added a mix of $1 \mu \mathrm{L}$ 2000 U/mL DNase I (M0303S, NEB, Ipswich, MA, USA), $2 \mu \mathrm{L}$ 10X DNase buffer (B0303S, NEB, Ipswich, MA, USA), and $7 \mu \mathrm{L}$ water. This was incubated for $40 \mathrm{~min}$ at $37^{\circ} \mathrm{C}$ and then $20 \mathrm{~min}$ at $80^{\circ} \mathrm{C}$. Phage stocks for the host range experiments (Section 2.5) were not treated with DNase prior to qPCR. In all subsequent experiments, we serially diluted phages in NB such that the addition of $100 \mu \mathrm{L}$ of diluted phage would achieve the intended multiplicity of infection (MOI), or number of phages per host cell. 


\subsection{Quantitative Real-Time PCR ( $q P C R)$}

Genome quantification with qPCR was performed as per the study in [16]. Briefly, each $20 \mu \mathrm{L}$ reaction consisted of $4 \mu \mathrm{L} 5 X$ EVOlution Probe qPCR Mix (Montreal Biotech Inc., Montreal, QC, Canada), $200 \mathrm{nM}$ of each primer, $100 \mathrm{mM}$ probe, and $2 \mu \mathrm{L}$ template. Primer and probe sequences are given in Table S1. Reaction conditions began with $10 \mathrm{~min}$ at $95^{\circ} \mathrm{C}$, followed by 40 cycles of $10 \mathrm{~s}$ at $95^{\circ} \mathrm{C}$ and $45 \mathrm{~s}$ at $54{ }^{\circ} \mathrm{C}$. The plasmid pTotalStdA [16] contains amplicons for E. amylovora and P. agglomerans, and the phages $\phi E$ E21-4, $\phi E a 46-1-A 1, \phi E a 9-2$, and $\phi E a 35-70$. Dilutions of pTotalStdA at $10^{11}, 10^{8}$, and $10^{5}$ copies $/ \mathrm{mL}$ were included in every run to generate the standard curve. Raw population quantities (genomes $/ \mathrm{mL}$ ) were calculated from their $\mathrm{Ct}$ values relative to the $\mathrm{Ct}$ values and copies $/ \mathrm{mL}$ of the pTotalStdA standard curve. Populations of bacteria and phage were directly interpreted from this curve on the assumption that each cell or phage capsid contained a single genome. qPCR quantification related to the host range (Section 2.5) was performed with a Stratagene Mx3005P qPCR System (Agilent Technologies, Santa Clara, CA, USA) and all others were performed with a qTower ${ }^{3}$ qPCR System (Analytik Jena, Jena, Germany).

\subsection{Population Dynamics of E. amylovora, P. agglomerans, and Different Phage Cocktails}

Initial liquid bacterial cultures were prepared to an $\mathrm{OD}_{600}$ of approximately 0.1 , or $10^{8} \mathrm{CFU} / \mathrm{mL}$, in $10 \mathrm{~mL}$ of NB. NA working subcultures were scraped into $3 \mathrm{~mL} \mathrm{NB}$ to an $\mathrm{OD}_{600}$ of 0.6 , or $10^{9} \mathrm{CFU} / \mathrm{mL}$. In a $50 \mathrm{~mL}$ conical tube, we added $100 \mu \mathrm{L}$ cell suspension to $10 \mathrm{~mL}$ refrigerated NB. In order to produce fresh and exponentially growing cells for the early morning, we incubated these cultures in a programmable shaking incubator (New Brunswick Innova 44R, Eppendorf, Mississauga, ON, Canada), which was maintained at $4{ }^{\circ} \mathrm{C}$ at $0 \mathrm{rpm}$ most of the night and switched to $27^{\circ} \mathrm{C}$ at $175 \mathrm{rpm}$ in the early morning to give roughly $5 \mathrm{~h}$ growth. The $\mathrm{OD}_{600}$ was measured until 0.1 was achieved, at which time these cultures were stored on ice until they were used to prepare the experimental cultures.

Experimental cultures throughout Sections 3.1 and 3.3 contain different bacterial and phage populations but were prepared in a modular fashion following a consistent methodology. Hosts tested include individual or combined cultures of Ea17-1-1, EaD7, 20060013, 20070126, Pa31-4, and Pa39-7. PaMix, EaMix, and EaWest were equal combinations of Pa31-4 and Pa39-7, Ea17-1-1 and EaD7, and 20060013 and 20070126, respectively. Phages tested include $\phi E a 21-4, \phi E a 46-1-A 1$, and $\phi E a 35-70$ individually and in combination. The bacteria and phages tested in each experiment are indicated within each figure. Into a $50 \mathrm{~mL}$ conical tube, we pre-aliquoted 9.5-9.9 mL NB such that the final culture volume was $10 \mathrm{~mL}$ after $100 \mu \mathrm{L}$ of all host cultures and phages were each added individually. First, phage dilutions were added such that the intended MOI would be achieved. Except where indicated within the figure, the intended MOI for all phages was 1 . Then, $100 \mu \mathrm{L}$ of the bacterial cultures were added such that the cultures initially contained $10^{6} \mathrm{CFU} / \mathrm{mL}$ total P. agglomerans or $10^{6} \mathrm{CFU} / \mathrm{mL}$ total E. amylovora. Cultures were grown at $27^{\circ} \mathrm{C}$ and $175 \mathrm{rpm}$ for $24 \mathrm{~h}$. Samples of $100 \mu \mathrm{L}$ were taken at 0,2 , $4,6,8$, and $24 \mathrm{~h}$ into microcentrifuge tubes; heated at $80^{\circ} \mathrm{C}$ for $20 \mathrm{~min}$; then frozen until qPCR analysis. DNA isolation and DNase treatment were not performed prior to qPCR. Samples were thawed before qPCR, and $2 \mu \mathrm{L}$ was used as template following the qPCR methodology in Section 2.3. All tests were performed with three experimental replicates, each measured with qPCR once.

\subsection{Phage Host Range Assay}

Phage host range was studied as per the work in [16], with the exception that phage were initially added at a starting concentration of $10^{6}$ genomes $/ \mathrm{mL}$. Hosts tested included all strains of P. agglomerans, Pantoea eucalypti, Erwinia gerundensis, Rahnella aquatilis, and Pantoea sp. in Table 1 with all 10 phages listed in Table 2. Host cultures were scraped from working subculture NA plates into $3 \mathrm{~mL}$ NB to an $\mathrm{OD}_{600}$ of 0.6 . In a $2 \mathrm{~mL}$ microcentrifuge tube, we added $100 \mu \mathrm{L}$ host cells and $100 \mu \mathrm{L}$ phage to $800 \mu \mathrm{L}$ NB. These cultures were incubated at $27^{\circ} \mathrm{C}$ and $200 \mathrm{rpm}$ for $8 \mathrm{~h}$. Cultures were heated for approximately $10 \mathrm{~min}$ over $70{ }^{\circ} \mathrm{C}$ to lyse the cells, stopping growth and releasing genomic DNA, 
and were then frozen until qPCR analysis. DNA isolation and DNase treatment were not performed prior to qPCR. Samples were thawed before $\mathrm{qPCR}$, and $2 \mu \mathrm{L}$ was used as a template following the qPCR methodology in Section 2.3. All combinations of host and phage were performed with three experimental replicates, each measured with qPCR once.

\subsection{Phage and Carrier Combinations for E. amylovora Reduction}

Experimental cultures were prepared the same as per Section 2.4, with the exception that EaMix was added to the culture either immediately $(0 \mathrm{~h})$ or after 2 or $8 \mathrm{~h}$ of culture growth. Cultures were grown at $27^{\circ} \mathrm{C}$ and $175 \mathrm{rpm}$. Samples of $100 \mu \mathrm{L}$ were taken upon addition of EaMix and $24 \mathrm{~h}$ after EaMix was added. These samples were heated at $80^{\circ} \mathrm{C}$ for $20 \mathrm{~min}$, then frozen until qPCR analysis. DNA isolation and DNase treatment were not performed prior to qPCR. Samples were thawed before qPCR, and $2 \mu \mathrm{L}$ was used as template following the qPCR methodology in Section 2.3. All experiments were performed with three experimental replicates, each measured with qPCR once.

\subsection{Genomic Sequencing of P. agglomerans and other Epiphytes}

Genomic DNA was isolated from overnight bacterial cultures using the Bacterial Genomic DNA Isolation Kit (17900; Norgen Biotek Corp., Thorold, ON, Canada). Paired-end library prep and MiSeq Illumina sequencing were performed by Genome Québec. Low-quality paired end reads were trimmed using Sickle, version 1.33 [32,33]. Sequences were assembled de novo using SPAdes assembler, version 3.11.1, in careful mode. The genomes were uploaded to GenBank and species identity was confirmed upon submission.

\subsection{Data Analysis}

Data analysis was performed in R version 3.5.1 [34]. Data manipulation and calculations were performed using the dplyr package, version 0.7.6 [35]. Genome quantities were $\log _{10}$ transformed before calculating mean population titers and bacterial reductions. Bacterial reductions at each time point were calculated as the difference between the $\log _{10}$ quantities of the treated sample and the untreated control. $\mathrm{MOI}_{\mathrm{g}}$, a genomic interpretation of $\mathrm{MOI}$ in real time, was calculated by dividing the untransformed genome quantity of phage by that of bacteria. In mixed cultures, the $\mathrm{MOI}_{\mathrm{g}}$ can be determined for each phage individually or as a sum of all phage genomes and for both bacterial host species separately. Linear regression was performed between the $\log _{10} \mathrm{OD}_{600}$ and $\log _{10}$ total host genome quantity of measured $24 \mathrm{~h}$ samples. The linear equation was then used to calculate the predicted genomic titer from the sample $\mathrm{OD}_{600}$ values and was compared to the qPCR measured quantities of E. amylovora in the presence and absence of P. agglomerans. Figures were generated with ggplot2, version 3.0.0 [36], using the packages scales, version 1.0.0 [37], and ggthemes, version 4.0.1 [38]. Statistical comparisons were performed using ANOVA followed by post hoc multiple comparison with Tukey's test, and differences were considered significant when $p<0.05$.

\section{Results}

\subsection{Population Dynamics of E. amylovora and Different Phage Cocktails}

The growth of both bacteria and phage can be monitored with qPCR as an increase in their respective genomes. Populations of different strains of E. amylovora infected with different phage cocktails were measured over time. In liquid culture at $27^{\circ} \mathrm{C}$, the growth of all uninfected E. amylovora strains were similar, reaching $10^{9}$ genomes $/ \mathrm{mL}$ after $8 \mathrm{~h}$ and not exceeding $10^{10}$ genomes $/ \mathrm{mL}$ after $24 \mathrm{~h}$ (Figure 1). Different strains were variably affected by the composition of the phage cocktails. The $\log _{10}$ reduction of each culture compared to the control was also determined (Figure S1). Reduction of Ea17-1-1 began after $8 \mathrm{~h}$ but only when $\phi$ Ea21-4 was present in the cocktail $(\bullet, \bullet, \bullet, \bullet ; p<0.05)$. The reduction of EaD7 began within $4 \mathrm{~h}$ in all cultures where $\phi \mathrm{Ea} 46-1-\mathrm{A} 1$ was present $(\bullet, \bullet, \bullet, \bullet ; p<0.05)$. Additionally, no culture's growth was affected by the presence of $\phi E a 35-70$ alone $(\bullet ; p>0.05)$. However, 
significant reduction after $24 \mathrm{~h}$ of Ea17-1-1 and EaD7 was only maintained when $\phi E a 35-70$ was combined with $\phi E a 21-4(\bullet, \bullet ; p<0.05)$ and $\phi E a 46-1-\mathrm{A} 1(\bullet, \bullet ; p<0.05)$, respectively. In a mixture of the two strains (EaMix), no single phage effectively reduced growth, and only cocktails containing both $\phi E a 21-4$ and $\phi E a 46-1-A 1$ started to slow growth after $6 \mathrm{~h}(\bullet, \bullet ; p<0.05)$. This remained consistent until $24 \mathrm{~h}$, and here additional synergy was observed with the inclusion of $\phi$ Ea35-70 $(\bullet ; p<0.05)$.

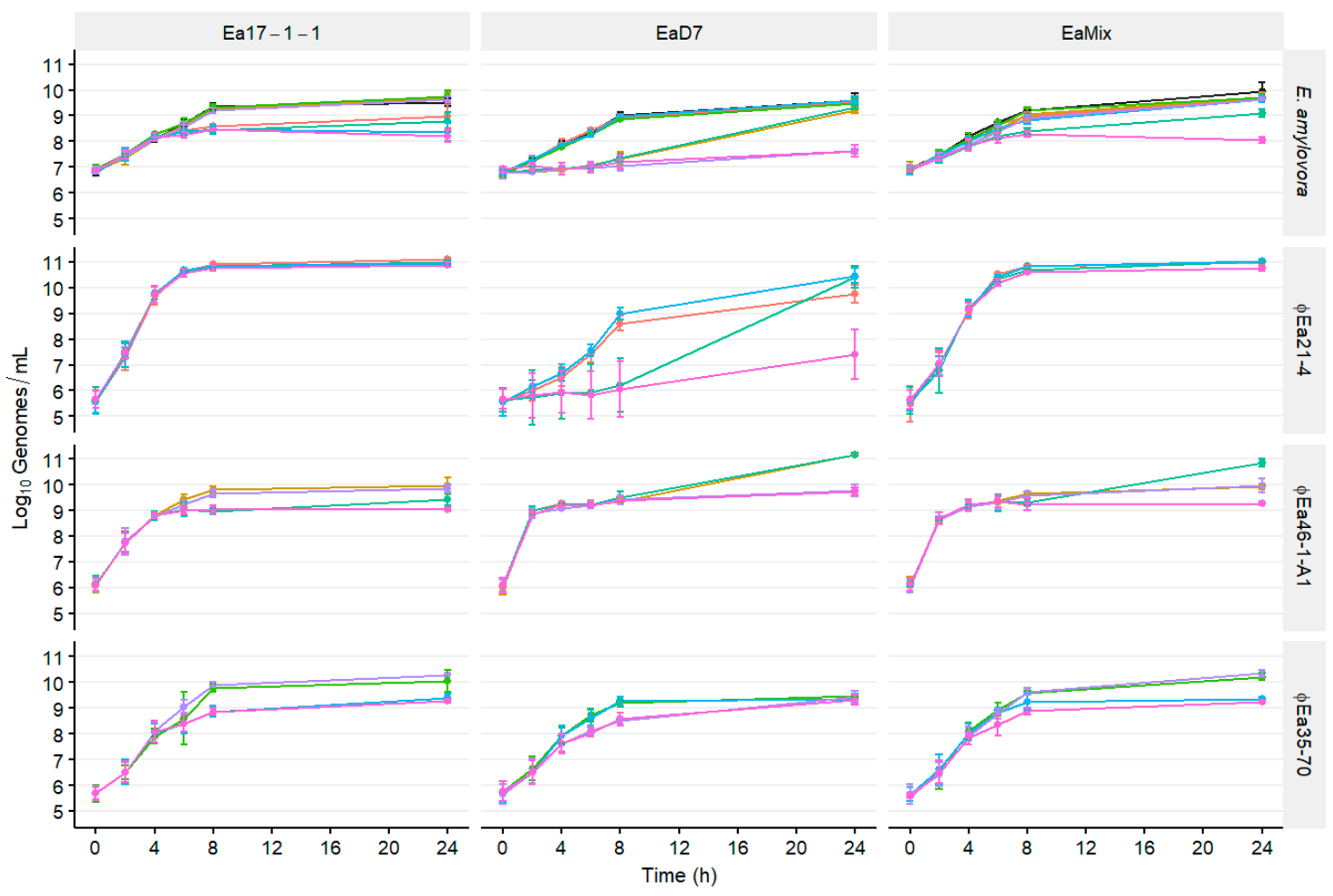

Figure 1. Populations of E. amylovora infected with different phage combinations over time. The infected strains Ea17-1-1, EaD7, and an equal mixture of both (EaMix) are indicated in the top banners. The banners on the right indicate the host or phage quantified. Each host was infected by all possible phage combinations, which are indicated by color: $\phi E a 21-4(\bullet), \phi E a 46-1-\mathrm{A} 1(\bullet), \phi E a 35-70(\bullet), \phi E a 21-4+\phi E a 46-1-\mathrm{A} 1(\bullet)$, $\phi \operatorname{Ea} 21-4+\phi \operatorname{Ea} 35-70(\bullet), \phi E a 46-1-A 1+\phi \operatorname{Ea35-70}(\bullet), \phi E a 21-4+\phi E a 46-1-A 1+\phi E a 35-70(\bullet)$, no phage $(\bullet)$. Genomic titers of E. amylovora and each phage were determined with qPCR. Data are the mean \pm SD of three replicates.

In liquid cultures, the phage populations were tracked alongside the bacterial hosts. The phage $\phi$ Ea21-4 was able to grow to over $1 \times 10^{10}$ genomes/mL with Ea17-1-1 and EaMix in $8 \mathrm{~h}$ and maintain this titer until $24 \mathrm{~h}$ (Figure 1). The growth of $\phi E a 21-4$ was also not influenced by the presence of other phages if Ea17-1-1 was also present. $\phi E a 21-4$ grew slower on EaD7 and did not reach a growth plateau by $8 \mathrm{~h}$. The initial growth of $\phi E a 21-4$ was reduced in the presence of $\phi E a 46-1-\mathrm{A} 1(\bullet, \bullet)$, and by $8 \mathrm{~h}$ was $2.41 \log$ units less than $\phi E a 21-4$ alone $(\bullet)$. Whereas $\phi E a 46-1-A 1$ reduced $\phi E a 21-4$ growth only up to $8 \mathrm{~h}$, both $\phi E a 46-1-\mathrm{A} 1$ and $\phi E a 35-70$ together reduced $\phi E a 21-4$ growth until $24 \mathrm{~h}$, at which time it only reached a titer of $1 \times 10^{7}$ genomes $/ \mathrm{mL}(\bullet)$. Notably, the growth of $\phi E a 21-4$ mirrored the growth of EaD7, whereby a reduction of EaD7 resulted in a reduction of $\phi E a 21-4$ (Figure 1). $\phi E a 46-1-A 1$, with its preferred host EaD7, increased nearly three log units in the first $2 \mathrm{~h}$, the fastest increase seen in any of the phage-host combinations (Figure 1). On Ea17-1-1, the phage took $4 \mathrm{~h}$ to increase the same amount, and on EaMix, production was similar to that of EaD7 and increased by $2.5 \log$ units in the first $2 \mathrm{~h}$. $\phi$ Ea35-70 grew similarly in all cultures, reaching around $10^{9}-10^{10}$ genomes $/ \mathrm{mL}$ at $8 \mathrm{~h}$ with reductions in cultures where host cell numbers were also reduced. 
With populations of both host and phages measured simultaneously using qPCR, we inferred the changing $\mathrm{MOI}$ as the ratio of phage genomes per host genome $\left(\mathrm{MOI}_{\mathrm{g}}\right)$. The control of E. amylovora (Figure S1) and the $\mathrm{MOI}_{\mathrm{g}}$ (Figure S2) are potentially linked. The time required to reduce the E. amylovora population by $0.25 \mathrm{log}$ units was phage-host-dependent: phage $\phi E a 21-4$ with Ea17-1-1 and $\phi E a 46-1-\mathrm{A} 1$ with EaD7 taking 6 and $2 \mathrm{~h}$, respectively. These times coincided with the time at which the $\mathrm{MOI}_{\mathrm{g}}$ approached 100 in each reaction. This was phage-host-dependent where only $\phi E a 21-4$ and $\phi E a 46-1-\mathrm{A} 1$ reached this level on Ea17-1-1 and EaD7, respectively. With EaMix, the MOI $I_{g}$ of $\phi E a 46-1-A 1$ only increased to 22 in $2 \mathrm{~h}$, while $\phi E a 21-4$ continued to reach an MOIg of 100 in $6 \mathrm{~h}$ (Figure S2). Reduction of the E. amylovora population in EaMix only exceeded $0.25 \mathrm{log}$ units at $4 \mathrm{~h}$ in cocktails containing $\phi$ Ea46-1-A1 $(\bullet, \bullet, \bullet, \bullet)$. Of these cocktails, only the two with $\phi$ Ea21-4 $(\bullet, \bullet)$ continued to further reduce the E. amylovora population to 6 and $8 \mathrm{~h}$ and only the three-phage cocktail $(\bullet)$ continued to control EaMix until $24 \mathrm{~h}$. By $24 \mathrm{~h}$, the three-phage cocktail ( $\bullet$ ) reduced the E. amylovora population by an additional log unit further than the $\phi E a 21-4+\phi E a 46-1-A 1$ cocktail $(\bullet)$.

Next, we investigated whether higher-starting MOIs would inhibit the growth of EaMix earlier (Figure 2). Moreover, we investigated whether this phage combination would still be effective against a mix of E. amylovora strains 20060013 and 20070126 from Utah, USA (EaWest), which we previously found to have some resistance to phages $\phi E a 46-1-A 1$ and $\phi E a 21-4$, respectively [16]. EaWest was still reduced by this phage combination, but significant control at $24 \mathrm{~h}$ required starting MOIs of 10 or 100 $(p<0.05)$. Interestingly, the maximal phage titers and initial rate of replication decreased as the starting MOI increased.

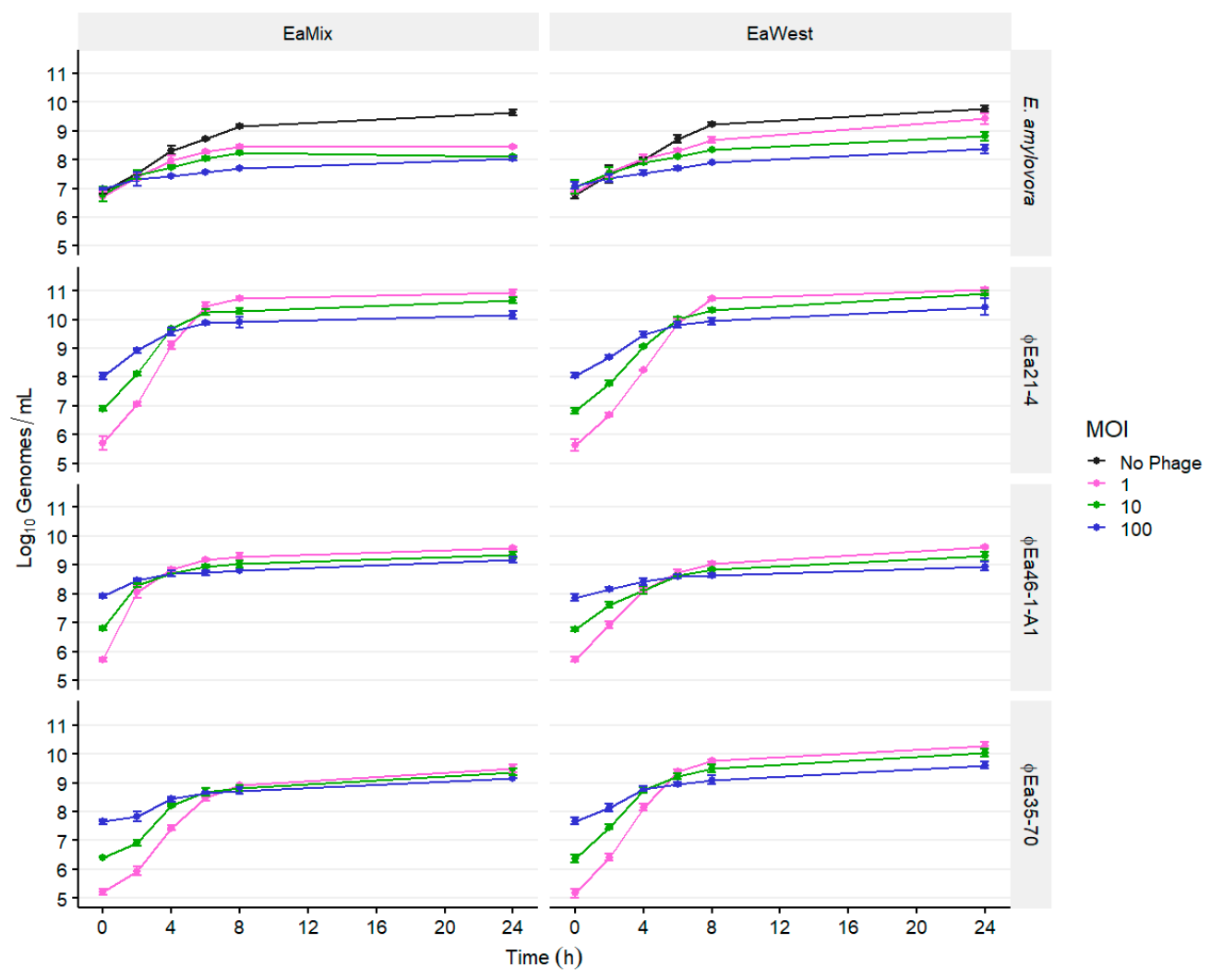

Figure 2. Populations over time of E. amylovora cultures infected with the three-phage cocktail at different starting multiplicities of infections (MOIs). The infected cultures were an equal combination of Ea17-1-1 and EaD7 (EaMix), and 20060013 and 20070126 (EaWest), and are indicated in the top banners. The banners on the right indicate the host or phage quantified. Each culture was infected simultaneously by the phages $\phi E a 21-4, \phi E a 46-1-A 1$, and $\phi E a 35-70$, each at the indicated MOI. Genomic titers of E. amylovora and each phage were determined with $\mathrm{qPCR}$. Data are the mean $\pm \mathrm{SD}$ of three replicates. 


\subsection{Host Range of Phages on Potential Carriers}

To identify which strains of $P$. agglomerans would be effective phage carriers, we performed a host range assay of 30 strains of $P$. agglomerans and other epiphytic bacteria with 10 phages [16]. The Podoviridae phages $\phi E \mathrm{Ea} 10-7, \phi \mathrm{Ea} 31-3$, and $\phi \mathrm{Ea} 46-1-\mathrm{A} 2$ were the only phages that did not increase by at least two $\log$ units $\left(>10^{8}\right.$ genomes/mL) on any hosts tested (Figure 3). Only two hosts (Pa17-1 and Pa39-7) were able to propagate at least one phage from each species to over $10^{8}$ genomes $/ \mathrm{mL}$.

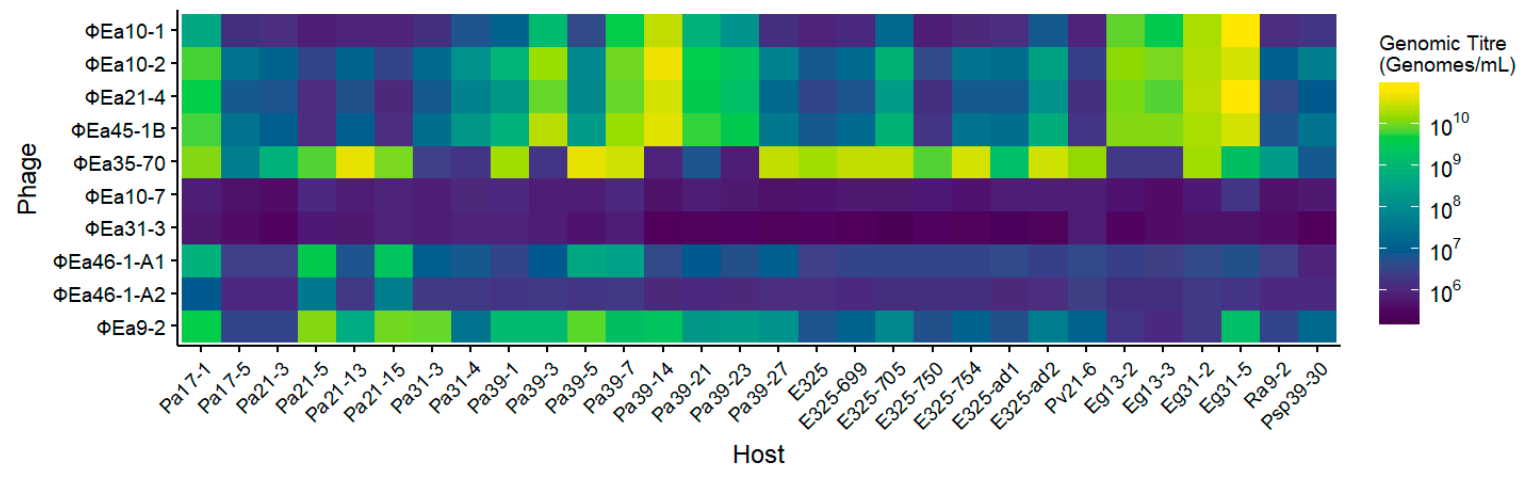

Figure 3. Host range of 10 E. amylovora phages against 30 strains of $P$. agglomerans and other epiphytic bacteria. The growth of phage is indicated by color, where yellow shows phage grew to $10^{11}$ genomes $/ \mathrm{mL}$ and blue indicates no growth beyond the initial titer of $10^{6}$ genomes $/ \mathrm{mL}$ after $8 \mathrm{~h}$ incubation. All hosts were initially identified as P. agglomerans through detection with PCR primers and subsequently corrected with genomic sequence data. Host species are indicated by their initial lettering: Pa and E325 (P. agglomerans); Pv (P. eucalypti); Eg (E. gerundensis); Ra (R. aquatilis); Psp (Pantoea sp.). Indicated titers are the geometric mean of three replicates.

Myoviridae phage $\phi$ Ea21-4 was propagated to over $10^{9}$ genomes $/ \mathrm{mL}$ in 10 hosts, including all four strains of Erwinia gerundensis and six strains of P. agglomerans (Figure 3). Interestingly, of those six strains of P. agglomerans, four were not hosts of Myoviridae phage $\phi E a 35-70$. Additionally, of the 26 hosts that propagated phages $\phi E a 21-4$ or $\phi E a 35-70$ to over $10^{8}$ genomes $/ \mathrm{mL}$, only seven hosts enriched both phages. In contrast, all five of the hosts that enriched $\phi E a 46-1-\mathrm{A} 1$ over $10^{8}$ genomes $/ \mathrm{mL}$ were good hosts of the other Podoviridae phage $\phi E a 9-2$. We chose to further investigate Pa39-7 as the carrier of the phages and Pa31-4 to grow unaffected by the phages. We hypothesized that in combination these two P. agglomerans strains would synergize to maximize control of E. amylovora.

\subsection{Population Dynamics of P. agglomerans and Different Phage Cocktails}

The growth of $P$. agglomerans was affected by the composition of phage cocktails (Figure 4, Figure S3). The growth of carrier Pa31-4 was not significantly affected by the presence of any phages $(p>0.05)$, whereas Pa39-7 was reduced by an average of 1.94 log units in cocktails containing $\phi$ Ea35-70 by $8 \mathrm{~h}(\bullet, \bullet, \bullet, \bullet ; p<0.05)$. Unexpectedly, the growth of the two carriers in combination (PaMix) was also affected by the presence of $\phi E a 35-70$, with an average log reduction of 1.64 at $8 \mathrm{~h}(p<0.05)$. Instead of Pa31-4 growing while only Pa39-7 was inhibited, which was what we expected, Pa31-4 growth was also reduced in this environment. After $24 \mathrm{~h}$, populations were no longer different $(p>0.05)$. 


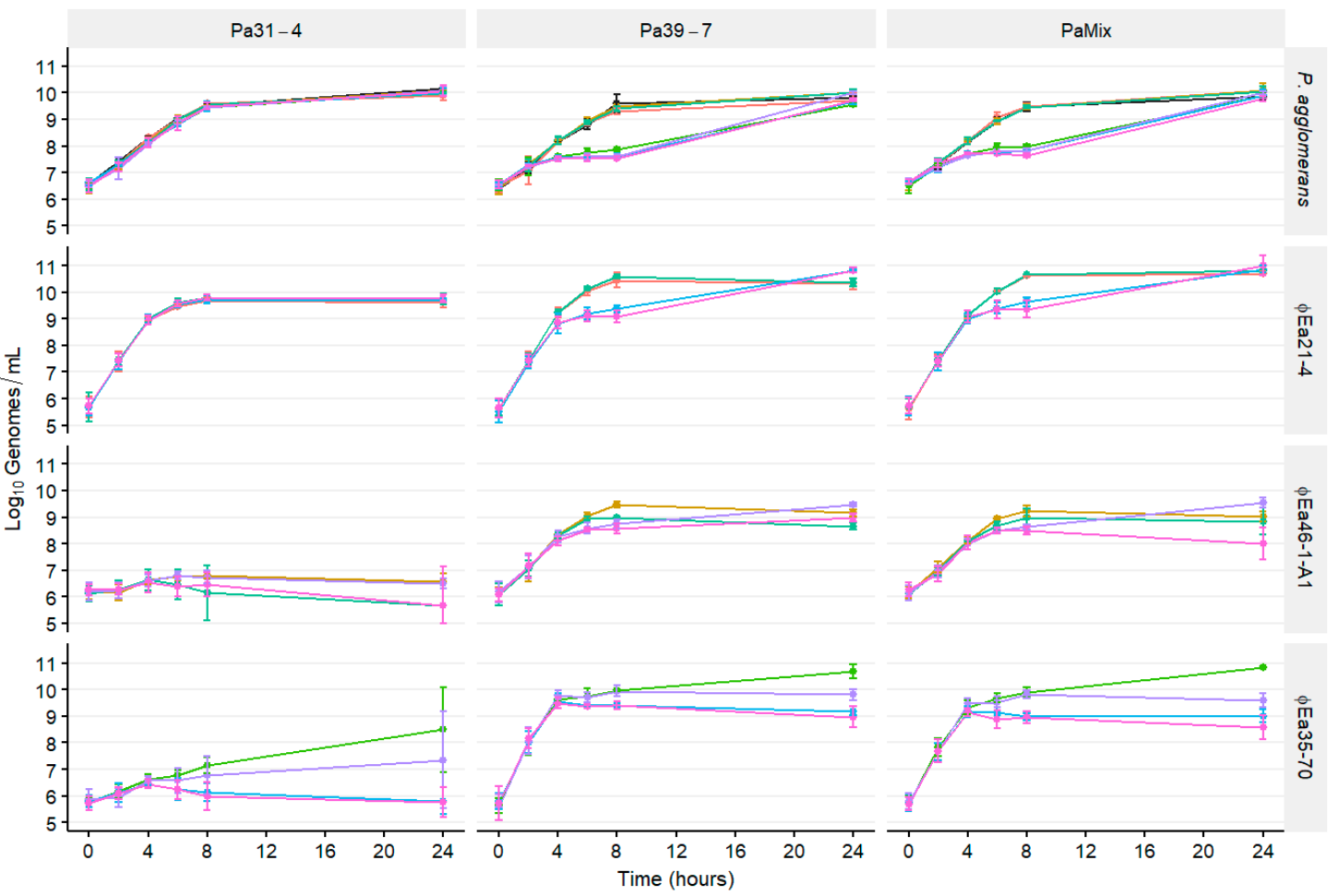

Figure 4. Populations over time of P. agglomerans cultures infected with different phage combinations. The infected strains Pa31-4, Pa39-7, and an equal combination of both (PaMix) are indicated in the top banners. The banners on the right indicate the host or phage quantified. Each host was infected by all possible phage combinations, which are indicated by color: $\phi E a 21-4(\bullet), \phi E a 46-1-\mathrm{A} 1(\bullet)$, $\phi \operatorname{Ea35-70}(\bullet), \phi \operatorname{Ea} 21-4+\phi \operatorname{Ea} 46-1-\mathrm{A} 1(\bullet), \phi E a 21-4+\phi E a 35-70(\bullet), \phi E a 46-1-A 1+\phi E a 35-70(\bullet)$, $\phi \mathrm{Ea} 21-4+\phi \mathrm{Ea} 46-1-\mathrm{A} 1+\phi \mathrm{Ea} 35-70(\bullet)$, no phage $(\bullet)$. Genomic titers of P. agglomerans and each phage were determined with qPCR. Data are the mean \pm SD of three replicates.

On carrier Pa31-4, $\phi$ Ea21-4 reached nearly $10^{10}$ genomes $/ \mathrm{mL}$ by $8 \mathrm{~h}$ and maintained this titer until $24 \mathrm{~h}(\bullet ;$ Figure 4). Moreover, $\phi E a 21-4$ growth was unaffected by the presence of other phages in the cocktail. Both $\phi E a 46-1-\mathrm{A} 1(\bullet)$ and $\phi E a 35-70(\bullet)$ grew minimally on Pa31-4, and in the presence of $\phi \operatorname{Ea} 21-4(\bullet, \bullet, \bullet)$ their final titers after $24 \mathrm{~h}$ were less than their initial titers. On Pa39-7, $\phi E a 21-4(\bullet)$ growth was perturbed in the presence of $\phi E$ Ea35-70 $(\bullet, \bullet)$ by $1.27 \log$ units by $8 \mathrm{~h}$, which coincided with a reduction of the Pa39-7. $\phi$ Ea35-70 growth $(\bullet)$ was affected by $\phi$ Ea21-4 $(\bullet, \bullet)$ starting at $6 \mathrm{~h}$, and also by $\phi$ Ea46-1-A1 (॰) at $24 \mathrm{~h}$. Growth of phages and hosts were similar for both Pa39-7 and PaMix (Figure 4).

Reduction of P. agglomerans populations (Figure S3) again coincided with the ratio of phage genomes to bacterial genomes (Figure S4). On Pa31-4, which was not reduced by any phage, only the $\mathrm{MOI}_{\mathrm{g}}$ of $\phi \mathrm{Ea} 21-4$ increased over time but never exceeded 10 throughout (Figure S4). On Pa39-7, the $\mathrm{MOI}_{\mathrm{g}}$ of $\phi$ Ea35-70 surpassed 100 at $4 \mathrm{~h}$, at which point the reduction of Pa39-7 exceeded 0.5 log units. The total $\mathrm{MOI}_{\mathrm{g}}$ remained over 100 until $8 \mathrm{~h}$, and the reduction continually increased to an average $1.94 \log$ units at $8 \mathrm{~h}$. Notably, on PaMix, the total MOI $\mathrm{g}_{\mathrm{g}}$ only reached 56.9 at $4 \mathrm{~h}$ with $\phi E a 35-70$-containing cocktails but the P. agglomerans population was still reduced by $0.48 \mathrm{log}$ units. While not as repressed as Pa39-7 alone, PaMix was still reduced by $1.64 \log$ units by $8 \mathrm{~h}$ by cocktails containing $\phi$ Ea35-70. Despite the high $\mathrm{MOI}_{\mathrm{g}}$, Pa39-7 and PaMix were able to recover and grow to the control by $24 \mathrm{~h}$ (Figure 4).

We then investigated whether we could further perturb $\phi E a 35-70$ enough to allow carrier growth to continue unaffected. We chose MOIs of 10, 1, and 0.01 of $\phi$ Ea21-4, $\phi E a 46-1-A 1$, and $\phi E a 35-70$, respectively, with PaMix ( $\left.3 \phi_{\mathrm{MOI}}\right)$ to compare against the MOI of $1(3 \phi)$, which was used in the previous experiments (Figure 5). The growth of PaMix with $3 \phi$ was again reduced from $4-8 \mathrm{~h}(p<0.05)$ but with $3 \phi_{\text {MOI }}$ was nearly identical to the uninfected control over $24 \mathrm{~h}(p>0.05)$. The phage $\phi E a 21-4$ 
genomic titer in the $3 \phi_{\mathrm{MOI}}$ cocktail remained approximately one log unit higher than $3 \phi$ for the first $8 \mathrm{~h}$, but by $24 \mathrm{~h}$ the titers of $\phi E a 21-4$ on both had reached $10^{11}$ genomes/mL. Phage $\phi E a 46-1-A 1$ was mostly unaffected by the change in MOI of the other phage, with differences not exceeding $0.5 \mathrm{log}$ units. Unfortunately, $\phi E a 35-70$ in $3 \phi_{\mathrm{MOI}}$ on PaMix did not reach $10^{7}$ when it reached its maximum after $4 \mathrm{~h}$ and slowly declined thereafter. Considering that $\phi$ Ea35-70 began at $10^{4}$ initially, there was still considerable phage production (Figure 5).

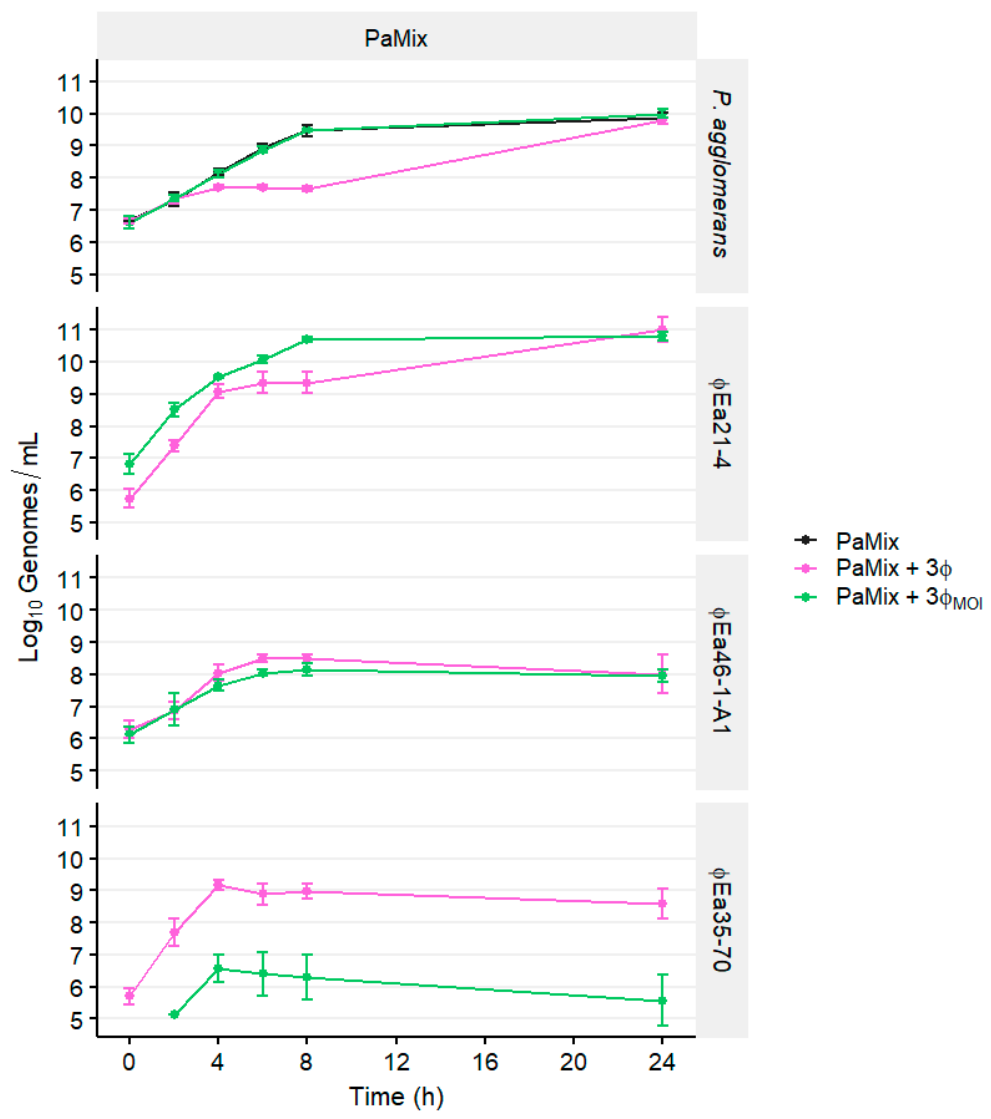

Figure 5. Effect of MOI on the growth of PaMix over $24 \mathrm{~h}$. PaMix was grown with no phage, or infected with the three phages $\phi E a 21-4, \phi E a 46-1-A 1$, and $\phi E a 35-70$, each at an MOI of 1 (3申) or at 10, 1, and 0.01, respectively $\left(3 \phi_{\mathrm{MOI}}\right)$. The banners on the right indicate the host or phage quantified. Genomic titers of P. agglomerans and each phage were determined with qPCR. Data are the mean \pm SD of three replicates. The missing data point for $\phi E a 35-70$ at $0 \mathrm{~h}(\bullet)$ was below the limit of detection.

\subsection{Phage and Carrier Combinations for E. amylovora Reduction}

To model how this chosen MOI $\left(3 \phi_{\text {MOI }}\right)$ would impact the survival of PaMix and subsequently control pathogen populations, we grew these treatments for different times before E. amylovora was introduced. When co-introduced $(0 \mathrm{~h})$, PaMix alone reduced EaMix by $0.83 \log$ units over $24 \mathrm{~h}$ (Figure 6). Treatments containing phage were more effective than PaMix alone, and the addition of PaMix with phage was no more effective than phage alone. With $2 \mathrm{~h}$ treatment growth before EaMix was added, none of the treatments were significantly more effective than they were at $0 \mathrm{~h}$, and only PaMix $+3 \phi_{\mathrm{MOI}}$ was more effective than PaMix alone. After $8 \mathrm{~h}$ prior treatment growth, PaMix $+3 \phi$ became less effective, but not significantly, when compared with PaMix alone, while PaMix $+3 \phi_{\text {MOI }}$ was the most effective treatment overall. Synergy between phage and carrier was seen only with $3 \phi_{\mathrm{MOI}}$ at 2 and $8 \mathrm{~h}$, wherein the treatment was more effective than phage or PaMix alone, reducing EaMix by 4.3 log units at $8 \mathrm{~h}$ (Figure 6). 


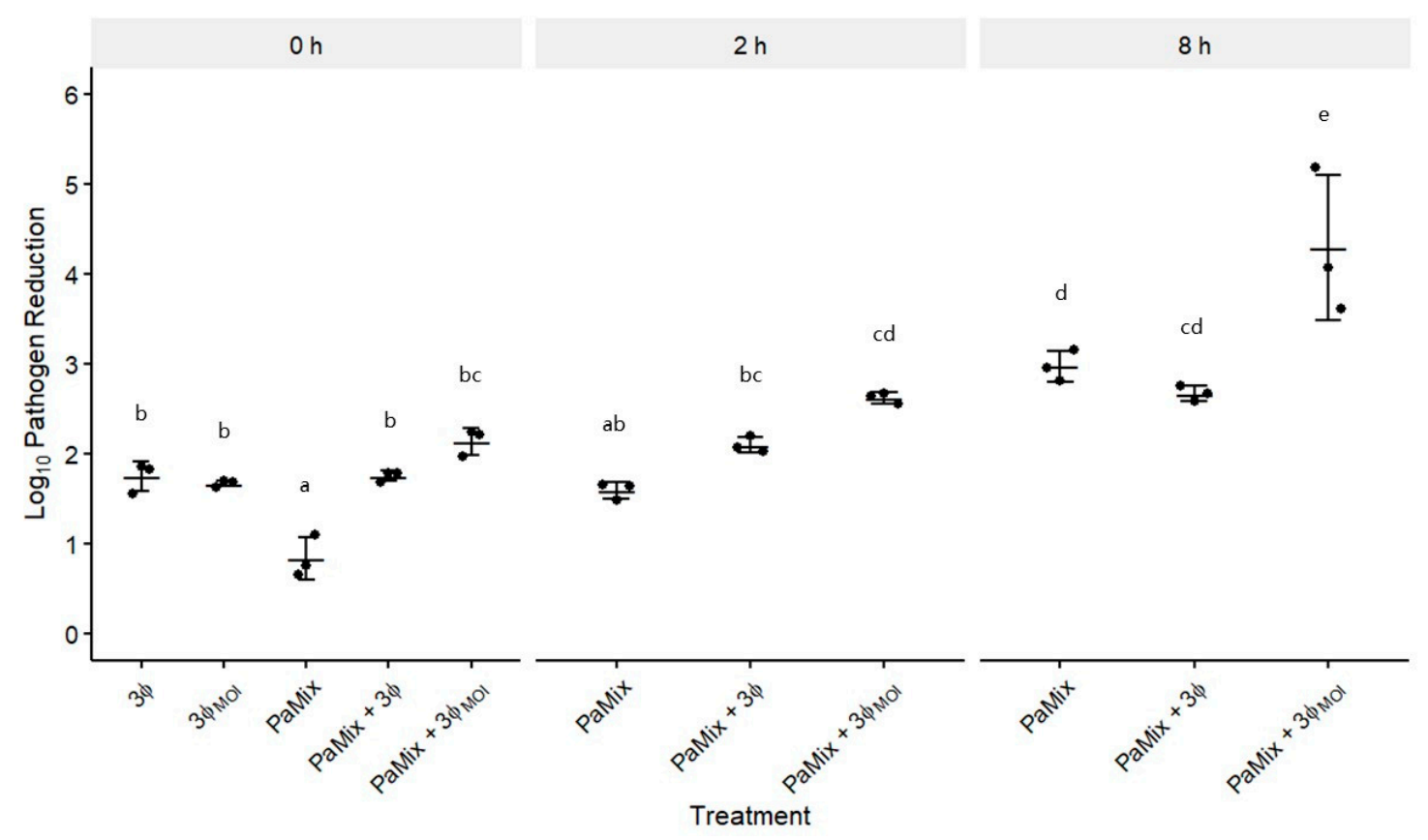

Figure 6. Effect of a designed MOI on the efficacy of PaMix and phage treatment at controlling E. amylovora. Treatments were grown for 0 (co-inoculated), 2, or $8 \mathrm{~h}$ before EaMix inoculation. The three phages $\phi E a 21-4, \phi E a 46-1-A 1$, and $\phi E a 35-70$, each at an MOI of $1(3 \phi)$ or at 10, 1, and 0.01, respectively, $\left(3 \phi_{\mathrm{MOI}}\right)$ were tested alone at $0 \mathrm{~h}$ or with PaMix at each time comparison. E. amylovora populations were measured $24 \mathrm{~h}$ after inoculation, and reduction was relative to EaMix growth alone. Data are the mean \pm SD of three replicates.

\subsection{Comparison of $q P C R$ and Spectrophotometry for Quantification of Mixed Bacterial Populations}

Measuring the optical density of a culture is a common alternative to directly counting viable colonies, especially when multiple measurements are made over time. To show that measuring host genomes with qPCR is comparable to optical density for bacterial quantification, we measured the $\mathrm{OD}_{600}$ of 90 experimental cultures at $24 \mathrm{~h}$ at the time they were sampled for qPCR. We plotted these $\mathrm{OD}_{600}$ values against the sum of all bacterial genomes detected with qPCR (Figure 7A). A regression of the total genomes determined with $\mathrm{qPCR}$ and $\mathrm{OD}_{600}$ of cultures showed that these were strongly correlated with an $R^{2}$ of 0.93 . Because optical density cannot differentiate bacterial species in liquid culture, we compared the qPCR titers of E. amylovora to the predicted bacterial genome titers calculated from the $\mathrm{OD}_{600}$ using the regression (Figure $7 \mathrm{~B}$ ). In cultures where EaMix was the only bacteria, optical density and qPCR populations were comparable between $10^{7}-10^{10}$ genomes $/ \mathrm{mL}$, with an average difference of only $0.026 \log$ units. However, when PaMix was also present, P. agglomerans often greatly outgrew E. amylovora by $24 \mathrm{~h}$, and optical density populations were an average of 1.97 log units higher than qPCR-determined titers of E. amylovora. This showed that not only is qPCR quantification highly comparable to optical density for cell quantification, but it can quantitatively differentiate different hosts in the culture, which is not easily done with optical density. 
A

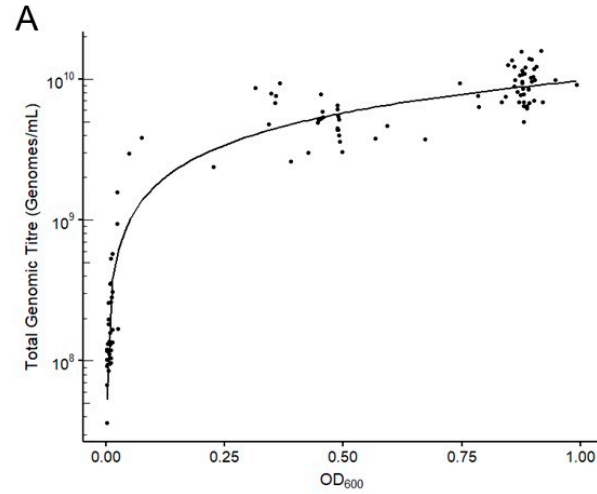

$\mathrm{B}$

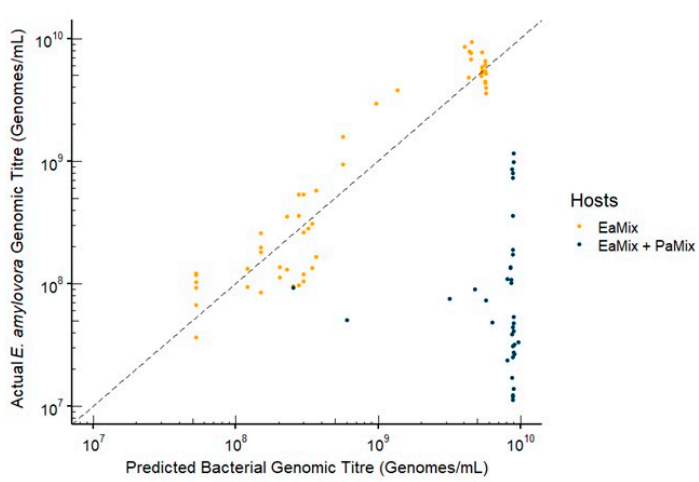

Figure 7. Correlation between $\mathrm{OD}_{600}$ and $\mathrm{qPCR}$ for quantification of E. amylovora in liquid culture. (A) A regression of total bacterial genomes (E. amylovora + P. agglomerans) in solution compared to $\mathrm{OD}_{600}$ was used to show the correlation and accuracy of qPCR $\left(R^{2}=0.93\right)$. (B) The regression was used to calculate the predicted titer of bacterial genomes on the basis of the $\mathrm{OD}_{600}$ of the solution, and this was compared to the actual qPCR-determined titer of E. amylovora genomes when E. amylovora was the only bacterium in solution $(\bullet)$ and when P. agglomerans was also present $(\bullet)$. The dotted line represents a 1:1 correlation between the predicted bacterial genomic titer calculated from the $\mathrm{OD}_{600}$ and the qPCR titer of E. amylovora.

\section{Discussion}

One of the greatest challenges in creating effective phage therapies is the translation of results from in vitro model systems to in vivo applications [4]. The goal of phage therapy is to modify the local microbiome in a way that prevents the pathogen from establishing within its niche and thereby preventing disease progression. To this end, model systems are first developed to gain a better understanding of the population dynamics within complex natural settings. As metagenomics and molecular technologies become more sophisticated, so too should the models of phage therapy. The aim of this study was to elucidate the dynamics between the pathogen E. amylovora, the carrier P. agglomerans, and cocktails of three potential therapeutic phages to facilitate the design of an effective phage and carrier combination treatment.

The effective control of a mixed E. amylovora population required the use of multiple phages (Figure 1, Figure S1). In previous work, phage $\phi E a 35-70$ showed no potential individually as an effective phage for biocontrol [16]. While $\phi E a 21-4$ and $\phi E a 46-1-A 1$ were each only effective against one strain, Ea17-1-1 and EaD7, respectively, $\phi E a 35-70$ synergized with both phages against their respective preferred host. Against a mixture of both strains (EaMix), $\phi E a 35-70$ also provided enhanced control with $\phi E a 21-4$ and $\phi E a 46-1-A 1$ together, maintaining the highest control at $24 \mathrm{~h}$. The reason for this synergy is unknown, but further investigation into the large genome and infection strategy of $\phi E a 35-70$ could yield novel insights into phage interactions. We also found this combination of phages to be effective at reducing the population of phage-resistant E. amylovora strains (Figure 2). This is essential to the continued effectivity of a phage-mediated biocontrol to prevent the development of phage resistance, given that different geographic regions, such as the west coast of North America, show varying levels of sensitively to these phages [16].

To maximize the biocontrol potential of a phage-carrier system, it is imperative that the carrier can quickly colonize the stigma surface. This is necessary for both competitive exclusion of E. amylovora and efficient production of the therapeutic phage. However, while including $\phi E a 35-70$ in the cocktail gave synergistic control of E. amylovora, this phage greatly impaired growth of P. agglomerans. Because we observed phage $\phi E a 21-4$ slowed replication of $\phi E a 35-70$ without affecting the growth of $P$. agglomerans (Figure 4), we chose the MOIs of 10, 1, and 0.01 for $\phi E a 21-4$, $\phi E a 46-1-A 1$, and $\phi E a 35-70$, respectively, to further investigate this dynamic. This optimized cocktail $\left(3 \phi_{\mathrm{MOI}}\right)$ no longer inhibited the planktonic

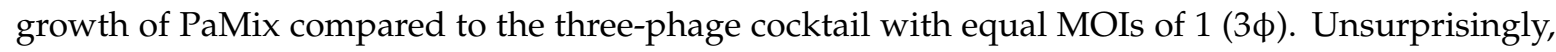


phage production in PaMix was also affected proportionally by the change in starting MOI (Figure 5). The higher $\phi E a 21-4$ production in $3 \phi_{\mathrm{MOI}}$ is potentially ideal for E. amylovora control, but the reduced titers of $\phi$ Ea35-70 could lead to decreased synergistic effects.

To emulate how biocontrol would occur in the field, we allowed our P. agglomerans and phage treatments to grow for 0,2 , and $8 \mathrm{~h}$ prior to addition of the pathogen (Figure 6). When co-introduced with EaMix, PaMix alone was least effective, but became more effective as it had more time to grow. While the addition of $3 \phi$ to PaMix was more effective than PaMix alone at $0 \mathrm{~h}$, there was no significant advantage over only $3 \phi$. Furthermore, any benefit from $3 \phi$ was lost over time as it became less effective than PaMix alone by $8 \mathrm{~h}$. Conversely, the optimization of the MOI of $3 \phi\left(3 \phi_{\mathrm{MOI}}\right)$ precluded the growth inhibition of the carrier, allowing the antagonistic effects of both P. agglomerans and the phages for enhanced control of the pathogen. As such, PaMix with $3 \phi_{\text {MOI }}$ was the most effective treatment at all time points.

The use of qPCR allowed the simultaneous tracking of pathogen, carrier, and phage populations in the growing cultures. This level of detail granted insights into the complex dynamics and interactions that occurred. While some studies or applications may require quantification of intact and infectious particles in specific environments through plaque assays, measuring the replication of phage genomes is an accurate and efficient way of observing changes in a mixed phage population. We showed previously that our qPCR methodology strongly correlates with dilution plating methods for quantification of both E. amylovora and P. agglomerans [26]. Here, we show this is also the case with optical density measurements of bacterial cultures (Figure 7A). Additionally, we show that optical density is not able to accurately quantify the minority population in mixed cultures (Figure 7B). While our qPCR methodology can differentiate E. amylovora and P. agglomerans, it is not specific enough to distinguish strains of the same species. Experimentation using mixed strain cultures is important for several reasons. The amount of capsular exopolysaccharides (EPS) produced by E. amylovora strains is known to significantly impact phage preference and infection [16,17]. EaMix consists of Ea17-1-1 and EaD7, which produce low and high amounts of EPS, respectively, and is therefore meant to represent the presence of both extremes found in natural populations. For example, choosing EaD7 exclusively would have resulted in high levels of control within in vitro experiments, but would be poorly representative of natural mixed infections found in vivo.

Pa31-4 and Pa39-7 in PaMix were chosen on the basis of the hypothesis that Pa39-7 would replicate the phages while Pa31-4, being phage resistant, would grow uninhibited and enhance the antagonistic effect against E. amylovora. It was therefore unexpected that Pa31-4 would be perturbed when combined with Pa39-7 and exposed to phage cocktails, which included $\phi E a 35-70$ (Figure 4). We observed that $\phi$ Ea35-70 was rapidly produced, presumably by Pa39-7, to an $\mathrm{MOI}_{\mathrm{g}}$ high enough that it inhibited Pa31-4 (Figure S4). This interaction highlights how phages can exhibit unexpected cascading effects on more diverse microbial populations, similar to how Hsu et al. showed phages applied to a gut microbiota induced cascading effects on non-target bacteria, and subsequently on gut metabolites as well.

The use of non-pathogenic strains or related species as phage carriers has been investigated but has generally received very little attention $[15,39,40]$. The host range of many phages are not as broad as the Erwinia phages studied here, and finding another wild-type host may be challenging [41]. Altered phage isolation methods can help find broader host range phages [41], or their host range can be directly modified with targeted mutagenesis [42] or editing phage tail genes [43,44]. Moreover, as more methods are developed for identifying the host genes necessary for phage infection [45], host genomes could also be edited to make them possible phage carriers [46]. Carriers could also be edited to provide additional antagonistic properties, potentially achieving new means of pathogen control [47]. Death of the bacterial carrier could also be a hindrance, but as we showed here this can be avoided or reduced with a greater understanding of the dynamics and interactions involved.

The roles that phages play in microbiomes remains under-investigated, especially in those of plants [48]. In animal hosts, phages have been shown to be linked to pathogenic microbial dysbiosis 
and can even interact with eukaryotic host cells directly [48,49]. Given the parallels between animal gut and rhizosphere microbiomes, it is suggestive of a larger, unrecognized role played by phages in plant health [48]. Recently, it was shown that phage alone affected the metabolism of Brassica oleracea var. gongylodes [50]. Given the continually emerging evidence that phages play a significant role in shaping microbial populations, a better understanding of the complex dynamics will be crucial for better implementations of phages in therapeutic applications. We have shown that even in our rudimentary model system there is enormous complexity in the dynamics and interactions that can be observed. The interactions that phages have on each other was of particular significance.

While we aimed to investigate the dynamics of complex populations, only a small fraction of the complexity of the actual microbiome on the blossom surface was the focal point of these studies. It remains unknown as to how these results will translate from liquid culture to the microenvironment of the blossom surface. To follow up with our findings, we aim to study these populations on the blossom surface in blossom assays and field experiments. Of particular importance is whether the $3 \phi_{\text {MOI }}$ cocktail will still allow the carrier to grow adequately in planta to cover the stigma surface and whether it will still synergize with the phages present. Additionally, further studies with more controlled and targeted changes to these cocktail and carrier combinations will allow us to further understand their interactions, allowing us to strive to maximize their potential therapeutic activity.

\section{Conclusions}

Our use of qPCR to study complex populations in liquid cultures made it possible to observe several unexpected dynamics that were exploited to create a phage and carrier combination for the control of E. amylovora. The jumbo Myoviridae phage $\phi E a 35-70$, while ineffective alone, synergized with both $\phi E a 21-4$ and $\phi E a 46-1-A 1$ for increased control of E. amylovora over $24 \mathrm{~h}$. However, at equal MOIs, this phage cocktail also reduced the growth of the bacterial carrier and antagonist P. agglomerans. To avoid this, we exploited the competition between $\phi E a 21-4$ and $\phi E a 35-70$ and chose to infect P. agglomerans with MOIs of 10, 1, and 0.01 for $\phi E a 21-4$, $\phi E a 46-1-\mathrm{A} 1$, and $\phi E a 35-70$, respectively. This modified phage combination no longer inhibited the growth of P. agglomerans and subsequently provided enhanced control of the pathogen. From these data, we observed examples of interspecies phage competition, synergy between multiple phages, and synergy between phages and a bacterial antagonist. All of these interactions could be significant factors to consider when designing phage cocktails or incorporating phages into IPM strategies.

Supplementary Materials: The following are available online at http:/www.mdpi.com/2076-2607/8/9/1449/s1.

Author Contributions: Conceptualization, S.G., A.J.C., and A.M.S.; methodology, S.G. and D.N.; validation, S.G.; formal analysis, S.G.; investigation, S.G.; resources, A.J.C. and A.M.S.; data curation, S.G. and M.P.; writing—original draft preparation, S.G.; writing—review and editing, S.G., M.P., A.J.C., and A.M.S.; visualization, S.G.; supervision, A.J.C. and A.M.S.; project administration, A.J.C. and A.M.S.; funding acquisition, A.J.C. and A.M.S. All authors have read and agreed to the published version of the manuscript.

Funding: This work was funded by the RGPIN-2016-05590 Natural Sciences and Engineering Research Council of Canada and Agriculture and Agri-Food Canada Growing Canadian Agricultural Partnership A-base grant.

Acknowledgments: We would like to thank Elton Pinto for his contributions to this work and Larry Pusey (retired, United States Department of Agriculture) for his generous donation of P. agglomerans E325 and its mutant strains. Genomic sequencing was performed by the Centre d'Expertise et de Services Génome Québec.

Conflicts of Interest: The authors declare no conflict of interest.

\section{References}

1. Clokie, M.R.; Millard, A.D.; Letarov, A.V.; Heaphy, S. Phages in nature. Bacteriophage 2011, 1, 31-45. [CrossRef] [PubMed]

2. Cycon, M.; Mrozik, A.; Piotrowska-Seget, Z. Antibiotics in the soil environment-degradation and their impact on microbial activity and diversity. Front. Microbiol. 2019, 10, 338. [CrossRef] [PubMed] 
3. Gordillo Altamirano, F.L.; Barr, J.J. Phage therapy in the postantibiotic era. Clin. Microbiol. Rev. 2019, 32, e00066-18. [CrossRef] [PubMed]

4. Bull, J.J.; Gill, J.J. The habits of highly effective phages: Population dynamics as a framework for identifying therapeutic phages. Front. Microbiol. 2014, 5, 618. [CrossRef] [PubMed]

5. Svircev, A.; Roach, D.; Castle, A. Framing the future with bacteriophages in agriculture. Viruses 2018, 10, 218. [CrossRef]

6. Krysiak-Baltyn, K.; Martin, G.J.; Stickland, A.D.; Scales, P.J.; Gras, S.L. Computational models of populations of bacteria and lytic phage. Crit. Rev. Microbiol. 2016, 42, 942-968. [CrossRef]

7. van der Zwet, T.; Orolaza-Halbrendt, N.; Zeller, W. Spread and current distribution of fire blight. In Fire Blight: History, Biology, and Management; The American Phytopathological Society: Saint Paul, MN, USA, 2016; pp. 15-36.

8. Pusey, P.L. The role of water in epiphytic colonization and infection of pomaceous flowers by Erwinia amylovora. Phytopathology 2000, 90, 1352-1357. [CrossRef]

9. van der Zwet, T.; Orolaza-Halbrendt, N.; Zeller, W. The disease cycle of fire blight. In Fire Blight: History, Biology, and Management; The American Phytopathological Society: Saint Paul, MN, USA, 2016; pp. 155-182.

10. Cui, Z.; Huntley, R.B.; Zeng, Q.; Steven, B. Temporal and spatial dynamics in the apple flower microbiome in the presence of the phytopathogen Erwinia amylovora. bioRxiv 2020. [CrossRef]

11. Steven, B.; Huntley, R.B.; Zeng, Q. The influence of flower anatomy and apple cultivar on the apple flower phytobiome. Phytobiomes. J. 2018, 2, 171-179. [CrossRef]

12. Stockwell, V.; Duffy, B. Use of antibiotics in plant agriculture. Rev. Sci. Tech. 2012, 31, 199-210. [CrossRef]

13. Pusey, P.L.; Stockwell, V.O.; Mazzola, M. Epiphytic bacteria and yeasts on apple blossoms and their potential as antagonists of Erwinia amylovora. Phytopathology 2009, 99, 571-581. [CrossRef] [PubMed]

14. Pusey, P.L.; Stockwell, V.O.; Reardon, C.L.; Smits, T.H.; Duffy, B. Antibiosis activity of Pantoea agglomerans biocontrol strain E325 against Erwinia amylovora on apple flower stigmas. Phytopathology 2011, 101, 1234-1241. [CrossRef] [PubMed]

15. Lehman, S.M. Development of a Bacteriophage-Based Biopesticide for Fire Blight. Ph.D. Thesis, Biological Sciences, Brock University, St. Catharines, ON, Canada, 2007.

16. Gayder, S.; Parcey, M.; Castle, A.J.; Svircev, A.M. Host range of bacteriophages against a world-wide collection of Erwinia amylovora determined using a quantitative PCR assay. Viruses 2019, 11, 910. [CrossRef]

17. Roach, D.R.; Sjaarda, D.R.; Castle, A.J.; Svircev, A.M. Host exopolysaccharide quantity and composition impact Erwinia amylovora bacteriophage pathogenesis. Appl. Environ. Microbiol. 2013, 79, 3249-3256. [CrossRef]

18. Alves, D.R.; Gaudion, A.; Bean, J.E.; Perez Esteban, P.; Arnot, T.C.; Harper, D.R.; Kot, W.; Hansen, L.H.; Enright, M.C.; Jenkins, A.T. Combined use of bacteriophage $\mathrm{K}$ and a novel bacteriophage to reduce Staphylococcus aureus biofilm formation. Appl. Environ. Microbiol. 2014, 80, 6694-6703. [CrossRef]

19. Alves, D.R.; Perez-Esteban, P.; Kot, W.; Bean, J.E.; Arnot, T.; Hansen, L.H.; Enright, M.C.; Jenkins, A.T. A novel bacteriophage cocktail reduces and disperses Pseudomonas aeruginosa biofilms under static and flow conditions. Microb. Biotechnol. 2016, 9, 61-74. [CrossRef] [PubMed]

20. Chan, B.K.; Sistrom, M.; Wertz, J.E.; Kortright, K.E.; Narayan, D.; Turner, P.E. Phage selection restores antibiotic sensitivity in MDR Pseudomonas aeruginosa. Sci. Rep. 2016, 6, 26717. [CrossRef]

21. Islam, M.S.; Zhou, Y.; Liang, L.; Nime, I.; Yan, T.; Willias, S.P.; Mia, M.Z.; Bei, W.; Connerton, I.F.; Fischetti, V.A.; et al. Application of a broad range lytic phage LPST94 for biological control of Salmonella in foods. Microorganisms 2020, 8, 247. [CrossRef]

22. Xie, Y.; Wahab, L.; Gill, J.J. Development and validation of a microtiter plate-based assay for determination of bacteriophage host range and virulence. Viruses 2018, 10, 189. [CrossRef]

23. Zaczek-Moczydlowska, M.A.; Young, G.K.; Trudgett, J.; Plahe, C.; Fleming, C.C.; Campbell, K.; O’Hanlon, R. Phage cocktail containing Podoviridae and Myoviridae bacteriophages inhibits the growth of Pectobacterium spp. under in vitro and in vivo conditions. PLOS ONE 2020, 15, e0230842. [CrossRef]

24. Kifelew, L.G.; Warner, M.S.; Morales, S.; Thomas, N.; Gordon, D.L.; Mitchell, J.G.; Speck, P.G. Efficacy of lytic phage cocktails on Staphylococcus aureus and Pseudomonas aeruginosa in mixed-species planktonic cultures and biofilms. Viruses 2020, 12, 559. [CrossRef] [PubMed] 
25. Duyvejonck, H.; Merabishvili, M.; Pirnay, J.P.; De Vos, D.; Verbeken, G.; Van Belleghem, J.; Gryp, T.; De Leenheer, J.; Van der Borght, K.; Van Simaey, L.; et al. Development of a qPCR platform for quantification of the five bacteriophages within bacteriophage cocktail 2 (BFC2). Sci. Rep. 2019, 9, 13893. [CrossRef] [PubMed]

26. Parcey, M.; Gayder, S.; Castle, A.J.; Svircev, A.M. Molecular profile of phage infection: A novel approach for the characterization of Erwinia phages through qPCR. Int. J. Mol. Sci. 2020, 21, 553. [CrossRef] [PubMed]

27. Evans, C.K. Survey results of Erwinia amylovora in Utah for resistance to streptomycin and investigations comparing kasugamycin (kasumin) to streptomycin and oxytetracycline for control of fire blight. Acta Hortic. 2008, 793, 433-437. [CrossRef]

28. Roach, D.R.; Sjaarda, D.R.; Sjaarda, C.P.; Ayala, C.J.; Howcroft, B.; Castle, A.J.; Svircev, A.M. Absence of lysogeny in wild populations of Erwinia amylovora and Pantoea agglomerans. Microb. Biotechnol. 2015, 8, 510-518. [CrossRef] [PubMed]

29. Gill, J.J.; Svircev, A.M.; Smith, R.; Castle, A.J. Bacteriophages of Erwinia amylovora. Appl. Environ. Microbiol. 2003, 69, 2133-21388. [CrossRef]

30. Lehman, S.M.; Kropinski, A.M.; Castle, A.J.; Svircev, A.M. Complete genome of the broad-host-range Erwinia amylovora phage $\phi E a 21-4$ and its relationship to Salmonella phage Felix O1. Appl. Environ. Microbiol. 2009, 75, 2139-2147. [CrossRef]

31. Yagubi, A.I.; Castle, A.J.; Kropinski, A.M.; Banks, T.W.; Svircev, A.M. Complete genome sequence of Erwinia amylovora bacteriophage vB_EamM_Ea35-70. Genome Announc. 2014, 2, e00413-e00414. [CrossRef]

32. Del Fabbro, C.; Scalabrin, S.; Morgante, M.; Giorgi, F.M. An extensive evaluation of read trimming effects on Illumina NGS data analysis. PLoS ONE 2013, 8, e85024. [CrossRef]

33. Joshi, N.A.; Fass, J.N. Sickle: A Sliding-Window, Adaptive, Quality-Based Trimming Tool for FastQ Files, Version 1.33; 2011. Available online: https://github.com/najoshi/sickle. (accessed on 4 March 2019).

34. R Core Team. R: A Language and Environment for Statistical Computing; Version 3.5.1; R Foundation for Statistical Computing: Vienna, Austria, 2018.

35. Wickham, H.; François, R.; Henry, L.; Müller, K. dplyr: A Grammar of Data Manipulation, R Package Version 0.7.6; 2018. Available online: https://CRAN.R-project.org/package=dplyr (accessed on 13 September 2018).

36. Wickham, H. ggplot2: Elegant Graphics for Data Analysis; R Package Version 3.0.0; Springer-Verlag: New York, NY, USA, 2016.

37. Wickham, H. Scales: Scale Functions for Visualization, R Package Version 1.0.0; 2018. Available online: https://CRAN.R-project.org/package=scales (accessed on 6 October 2018).

38. Arnold, J.B. ggthemes: Extra Themes, Scales and Geoms for 'ggplot2', R Package Version 4.0.1; 2018. Available online: https://CRAN.R-project.org/package=ggthemes (accessed on 6 October 2018).

39. Danelishvili, L.; Young, L.S.; Bermudez, L.E. In vivo efficacy of phage therapy for Mycobacterium avium infection as delivered by a nonvirulent mycobacterium. Microb. Drug Resist. 2006, 12, 1-6. [CrossRef]

40. Tanaka, H.; Negishi, H.; Maeda, H. Control of tobacco bacterial wilt by an avirulent strain of Pseudomonas solanacearum M4S and its bacteriophage. Jpn. J. Phytopathol. 1990, 56, 243-246. [CrossRef]

41. Ross, A.; Ward, S.; Hyman, P. More is better: Selecting for broad host range bacteriophages. Front. Microbiol. 2016, 7, 1352. [CrossRef] [PubMed]

42. Yehl, K.; Lemire, S.; Yang, A.C.; Ando, H.; Mimee, M.; Torres, M.T.; de la Fuente-Nunez, C.; Lu, T.K. Engineering phage host-range and suppressing bacterial resistance through phage tail fiber mutagenesis. Cell 2019, 179, 459-469. [CrossRef] [PubMed]

43. Yosef, I.; Goren, M.G.; Globus, R.; Molshanski-Mor, S.; Qimron, U. Extending the host range of bacteriophage particles for DNA transduction. Mol. Cell 2017, 66, 721-728. [CrossRef] [PubMed]

44. Ando, H.; Lemire, S.; Pires, D.P.; Lu, T.K. Engineering modular viral scaffolds for targeted bacterial population editing. Cell Syst. 2015, 1, 187-196. [CrossRef]

45. Rousset, F.; Cui, L.; Siouve, E.; Becavin, C.; Depardieu, F.; Bikard, D. Genome-wide CRISPR-dCas9 screens in E. coli identify essential genes and phage host factors. PLoS Genet. 2018, 14, e1007749. [CrossRef]

46. Zeng, Z.; Salmond, G.P.C. Bacteriophage host range evolution through engineered enrichment bias, exploiting heterologous surface receptor expression. Environ. Microbiol. 2020. [CrossRef]

47. Jensen, D.F.; Karlsson, M.; Sarrocco, S.; Vannacci, G. Biological control using microorganisms as an alternative to disease resistance. In Plant Pathogen Resistance Biotechnology; Collinge, D.B., Ed.; John Wiley \& Sons, Inc.: Hoboken, NJ, USA, 2016; pp. 341-363. 
48. Pratama, A.A.; Terpstra, J.; de Oliveria, A.L.M.; Salles, J.F. The role of rhizosphere bacteriophages in plant health. Trends Microbiol. 2020, 28, 709-718. [CrossRef]

49. Barr, J.J. A bacteriophages journey through the human body. Immunol. Rev. 2017, 279, 106-122. [CrossRef]

50. Papaianni, M.; Paris, D.; Woo, S.L.; Fulgione, A.; Rigano, M.M.; Parrilli, E.; Tutino, M.L.; Marra, R.; Manganiello, G.; Casillo, A.; et al. Plant dynamic metabolic response to bacteriophage treatment after Xanthomonas campestris pv. campestris infection. Front. Microbiol. 2020, 11, 732. [CrossRef]

(c)

(C) 2020 by the authors. Licensee MDPI, Basel, Switzerland. This article is an open access article distributed under the terms and conditions of the Creative Commons Attribution (CC BY) license (http://creativecommons.org/licenses/by/4.0/). 